\title{
DA MODERNIZAÇÃO AGRÍCOLA À DINÂMICA DE DESENVOLVIMENTO RURAL: O ASSENTAMENTO MAISA, RIO GRANDE DO NORTE
}

\author{
FROM AGRICULTURAL MODERNIZATION TO THE DYNAMICS OF RURAL DEVELOPMENT: \\ THE MAISA SETTLEMENT IN THE STATE OF RIO GRANDE DO NORTE, BRAZIL
}

\author{
DE LA MODERNIZACIÓN AGRÍCOLA A LA DINÁMICA DEL DESARROLLO RURAL: \\ EL ASENTAMIENTO MAISA, EN RIO GRANDE DO NORTE, BRASIL
}

\author{
Kerginaldo Nogueira de Medeiros ${ }^{1}$ \\ https://orcid.org/0000-0002-6093-7335 \\ Emanoel Márcio Nunes ${ }^{2}$ \\ https://orcid.org/0000-0002-9045-887X \\ Samara de Melo Ramalho ${ }^{3}$ \\ https://orcid.org/0000-0002-1316-2872
}

Submissão: 30/11/2020 / Aceito: 16/03/2021 / Publicado: 31/03/2021.

\begin{abstract}
Resumo
O objetivo do artigo é analisar a agricultura familiar no assentamento MAISA, como uma dinâmica de desenvolvimento rural no Rio Grande do Norte, considerando sua passagem de empresa agrícola moderna e exportadora desde os anos 1970, para se transformar no segundo maior assentamento de reforma agrária do Brasil a partir do ano de 2003. A metodologia consistiu no estudo de dez dinâmicas internas, as agrovilas, com a aplicação de questionários para 89 famílias de agricultores assentados. Os resultados mostram uma baixa produtividade agrícola, uso de tecnologia atrasada e de baixo custo, além de grande parte dos chefes das famílias sendo empregados em empresas agrícolas, reproduzindo a própria condição de quando eram empregados da própria empresa MAISA. Conclui-se que o acesso a programas estatais assistencialistas se apresenta como estratégia para completar a renda familiar. A maior parte do excedente da produção é destinada a atravessadores, com inexpressível acesso aos mercados institucionais. Inexiste organização coletiva, se limitando a gestão da infraestrutura das agrovilas. Apesar desse contexto, a pesquisa constatou que a maioria das famílias demonstra otimismo em relação ao futuro e satisfação com as atividades agrícolas e com o meio rural.
\end{abstract}

Palavras-chave: Modernização agrícola, Reforma Agrária, Agricultura familiar, Ruralidade.

\footnotetext{
${ }^{1}$ Mestrado pelo Programa de Pós-Graduação em Ambiente, Tecnologia e Sociedade (PPGATS/UFERSA), Mossoró, RN, Brasil. E-mail: kerginaldo@ufersa.edu.br

${ }^{2}$ Doutor, Professor, Universidade do Estado do Rio Grande do Norte (UERN), Programas de Pós-Graduação em Economia (PPE/UERN), e em Planejamento e Dinâmicas Territoriais do Semiárido (PLANDITES/UERN), Mossoró, RN, Brasil. E-mail: emanoelnunes@uern.br

${ }^{3}$ Mestranda pelo Programa de Pós-Graduação em Economia (PPE/UERN), Mossoró, RN, Brasil. E-mail: samaramelo64@gmail.com
} 


\begin{abstract}
This paper is aimed at analyzing family farming in the MAISA settlement, as a dynamics of rural development in the state of Rio Grande do Norte, Brazil, considering the change from a modern and exporting agricultural company since the 1970s into Brazil's second larger land reform settlement since 2003. The methodology consisted of studying ten settlement dynamics, the agro-villages, by applying surveys to 89 families of settled farmers. The results presented low agricultural productivity, use of backward and low-cost technology, and most of heads of families being employed in agricultural companies, similar to when they worked for MAISA. It is concluded that the access to public welfare programs is presented as a strategy to supplement the family income. Most of the production surplus is destined to middlemen, and institutional markets get inexpressible access to it. There is no collective organization. It is limited to the agro-village infrastructure management. And despite this context, it was found that most families are optimistic about the future and satisfied with the agricultural activities and the rural environment.
\end{abstract}

Keywords: Agricultural modernization. Land reform. Family farming. Rurality.

\title{
Resumen
}

El objetivo del artículo es analizar la agricultura familiar en el asentamiento MAISA, como una muestra dinámica del desarrollo rural en Rio Grande do Norte, considerando su transcurso de una empresa agrícola moderna y exportadora desde la década de 1970, hasta convertirse en el segundo asentamiento de reforma agraria más importante del país. Brazil a partir de 2003. La metodología consistió en el estudio de diez dinámicas internas, las agroaldeas, con la aplicación de cuestionarios a 89 familias de agricultores asentados. Los resultados muestran una baja productividad agrícola, uso de tecnología atrasada y de bajo costo, además de que gran parte de los jefes de familia están empleados en empresas agrícolas, reproduciendo la misma condición de cuando eran trabajadores de la propia empresa MAISA. Se concluye que el acceso a los programas estatales de bienestar se presenta como una estrategia para complementar el ingreso familiar, la mayor parte del excedente de producción se destina a intermediarios, con acceso inexpresivo a los mercados institucionales. No existe una organización colectiva, limitándose a la gestión de la infraestructura de la agro-aldea. A pesar de este contexto, la encuesta encontró que la mayoría de las familias muestran optimismo sobre el futuro y satisfacción con las actividades agrícolas y el medio rural.

Palabras clave: modernización agraria, reforma agraria, agricultura familiar, ruralidad.

\section{INTRODUÇÃO}

A modernização agrícola brasileira teve como característica a implantação de tecnologias modernas na produção no meio rural, onde as atividades agrícolas passaram a se atrelar ao ritmo da indústria e em constante inovação, buscando alcançar maior produção e níveis cada vez mais altos de produtividade. O processo de modernização da agricultura ocorreu de forma mais intensa no período de 1965 a 1985, baseado na crença em grandes empresas, no modelo exportador e envolveu um grande aparato tecnológico e financeiro, 
seguindo o movimento mundial conhecido como revolução verde. No entanto, a crise macroeconômica brasileira dos anos 1980 comprometeu o desempenho desse processo de modernização no país e desencadeou, a partir dos anos 1990 e 2000, o surgimento de dinâmicas de desenvolvimento rural baseadas no mercado interno, na diversificação da agricultura familiar e na capacidade dos agricultores e suas organizações coletivas.

Foi na esteira do processo de modernização que a Mossoró Agroindustrial S.A. (MAISA) foi fundada, no ano de 1968, encerrando as suas atividades e se transformando em assentamento de reforma agrária no ano de 2003. Essa passagem revela importância para uma avaliação do desempenho recente do agora assentamento MAISA, como uma dinâmica de desenvolvimento rural estruturada no lugar do que antes foi considerada uma próspera e destacada empresa moderna e exportadora de frutas do país. E a avaliação pode ser maximizada pela inexistência de dados oficiais que considerem os projetos de reforma agrária como unidade de análise específica. Investigar os agricultores familiares inseridos no assentamento MAISA com o devido reconhecimento das suas peculiaridades é assumir a sua importância na dinâmica do desenvolvimento rural.

A mistura dos parâmetros conceituais do desenvolvimento rural, da agricultura familiar e da reforma agrária constitui um instigante tema para a avaliação do ponto de vista sociológico, econômico, administrativo e produtivo. E esse contexto de diversidade, que se apresenta como favorável para o segmento da agricultura familiar, deve ser considerado quando na análise envolve regiões com condições climáticas adversas, a exemplo da região Nordeste do Brasil e seus períodos de estiagem. A seca sempre fez parte do cenário do Nordeste brasileiro, e as ações governamentais de ampliação da reforma agrária devem levar em conta a sua importância na região, quando no sentido de promover a distribuição fundiária e de renda, a dinamização territorial, a segurança alimentar, o respeito à cultura local, visando consolidar dinâmicas de desenvolvimento rural sustentável.

Por sua vez, o desenvolvimento rural deve ser analisado a partir de uma perspectiva que ultrapassa a análise unilateral da produtividade agrícola, incluindo estratégias nas formas de organização da produção e de acesso aos mercados, e a intervenção estatal através de políticas públicas, bem com as representações dos agricultores sobre a ruralidade e seu futuro. Baseando-se nas teorias de crescimento versus desenvolvimento, a questão central é: como aconteceu a passagem de uma grande empresa agrícola baseada em modelos exógenos para o Assentamento MAISA, no Rio Grande do Norte; e como os agricultores familiares vêm 
elaborando estratégias para construir e viabilizar uma dinâmica de desenvolvimento rural, onde antes existia uma grande empresa moderna e exportadora?

A hipótese que se apresenta é a de que uma parte significativa dos chefes das famílias do assentamento MAISA pouco produzem nas suas áreas, e se mantêm mais como empregados em empresas agrícolas fora ou com transferências, a exemplo de aposentadorias, Bolsa Família, etc. Dessa maneira, os agricultores familiares mantêm uma realidade de baixa produtividade agrícola e de organização coletiva, o que dificulta a viabilidade de todo o Assentamento MAISA, além de reproduzirem o papel de empregados, o mesmo que desempenhavam na época em que eram empregados da empresa MAISA.

O objetivo do artigo é analisar a agricultura familiar presente no Assentamento MAISA, no Rio Grande do Norte, fazendo uma relação entre dois momentos: de uma grande empresa agrícola moderna dos anos 1970 a 2002, à tentativa de uma dinâmica de desenvolvimento rural por meio da agricultura familiar no âmbito da reforma agrária, a partir de 2003. Cabe ressaltar que a análise considera processos de intervenção estatal no sentido da estruturação produtiva, orientação tecnológica e de organização social e coletiva.

\section{A MODERNIZAÇÃo E O MODELO ESPECIALIZADO DE CRESCIMENTO AGRÍCOLA}

Para Souza (2005), as perspectivas do crescimento dão ênfase apenas a acumulação, na defesa de uma lógica única e padrão de solução reducionista da realidade, em que os países são considerados homogêneos dentro da mesma problemática de análise. E para uma melhor compreensão do processo de modernização da agricultura brasileira, baseado em modelos exógenos e especializados de crescimento agrícola, se faz necessário o destaque de duas perspectivas visando interpretar e expor as referências teóricas de crescimento versus desenvolvimento econômico: a ortodoxia keynesiana e a corrente neoclássica.

A ortodoxia keynesiana, segundo Souza (2005), se constitui uma doutrina políticoeconômica que tem no Estado um agente protagonista do crescimento econômico, no sentido do combate a recessão e aos elevados níveis de desemprego. Para isso, Keynes (1982) recorre à quarta das suas cinco inovações da obra Teoria Geral do Emprego, do Juro e da moeda, em que "o papel dos gastos públicos como suplemento ao dispêndio privado" passa a exigir um Estado maior e mais ativo como estruturador econômico e estimulador dos investidores privados, estes últimos considerados os principais decisores do processo de crescimento da 
economia de um país. A doutrina keynesiana vem abalar a crença da Escola Clássica que defendia de forma irredutível o mecanismo automático e único do mercado como garantia de pleno emprego, gerando uma oposição ao liberalismo que defendia um Estado fora da economia ou no menor tamanho possível.

Conforme Souza (2005), a perspectiva da doutrina keynesiana se sustenta na ideia de que o crescimento econômico é provocado e disparado por meio de uma relação direta entre o nível de investimentos, poupança de um país e o ritmo de crescimento de seu Produto Interno Bruto (PIB). Na perspectiva da economia keynesiana, o crescimento econômico é traduzido como uma variação quantitativa dos principais agregados macroeconômicos, ou seja, o PIB, a Renda Nacional e o Emprego, e os investidores definem o nível de investimento de acordo com as suas expectativas, as quais decidirão sobre os níveis de investimento do longo prazo. A doutrina keynesiana conforme Gonçalves Neto (1997), Graziano da Silva (1996) e Delgado (2012), influenciou governos, a exemplo do governo brasileiro a partir de 1965 com a estruturação de complexos agroindustriais pelo Estado no sentido de modernizar a agricultura. Assim, foram criados o Sistema Nacional de Crédito Rural (SNCR), a Empresa Brasileira de Pesquisa Agropecuária (EMBRAPA), a Empresa Brasileira de Assistência Técnica e Extensão Rural (EMBRATER), a Companhia Nacional de Armazéns (CIBRAZEM), entre outras.

Quanto a escola neoclássica, a ideia de crescimento é estruturada a partir da relação entre o Produto Interno Bruto per capita e o capital físico. Para Souza (2005), a perspectiva neoclássica considera um ambiente com e sem o progresso técnico, onde o crescimento econômico é explicado por meio de uma variável exógena, e considera a existência de um limite máximo ao crescimento definido steady-state, ou estado estacionário. Neste sentido, o crescimento real do PIB tende e deve ser igual ao crescimento da população adicionada à taxa de progresso técnico, o que para os economistas defensores desta perspectiva, como Robert Solow, isso implica que o PIB per capita seja sempre constante.

A corrente neoclássica influenciou muitas das contribuições teóricas voltadas para a modernização da agricultura no mundo. No Brasil foram adotadas obras, a exemplo da de Hayami \& Ruttan (1985) sobre inovação técnica e institucional induzida, que influenciou vários pesquisadores defensores das explicações exógenas dos modelos de crescimento agrícola. Dos autores nacionais, destacam-se Paiva (1971) e Schuh (1975), tendo o primeiro tratado dos graus de modernização dos agricultores e das vantagens do mecanismo de 
autocontrole na agricultura, e o segundo sobre a adoção de tecnologias externas e a interpretação neoclássica da modernização da agricultura brasileira.

As duas teorias do crescimento econômico foram apontadas com a finalidade de interpretar e melhor explicar a concepção de criação no ano de 1968, e do funcionamento até o ano de 2003, da empresa Mossoró Agroindustrial S.A. (MAISA). A empresa MAISA, situada em Mossoró, estado do Rio Grande do Norte, surgiu como uma grande empresa agrícola precursora da fruticultura irrigada de exportação no semiárido nordestino, e constituiu a representação da crença da modernização agrícola brasileira, baseada em um modelo exógeno e especializado de crescimento agrícola. No seu auge, foi responsável por gerar mais de 4.000 empregos diretos, nas décadas de 1980 e 1990, e tinha como principal atividade econômica a produção de frutas frescas, especialmente melões para a exportação.

A empresa foi pioneira no cultivo de melão irrigado no Rio Grande do Norte, utilizando técnicas modernas de explicações exógenas, a exemplo da crença neoclássica, com a utilização intensiva de insumos externos e a prática de irrigação, a partir da exploração de poços com profundidade média de 700 metros. Segundo Sá (2003), a produtividade da empresa era de aproximadamente 80 toneladas por hectare, e num determinado ano obteve com a comercialização para o exterior aproximadamente US\$20.000.000, representando $20 \%$ de toda exportação de frutas "in natura" do país. $\mathrm{Na}$ época, esses números impressionavam, considerando a hostilidade das condições climáticas e da ainda mentalidade de não acreditar muito nos investimentos na agricultura do semiárido.

De acordo com Nunes e Schneider (2012), a MAISA iniciou suas atividades em 1968 com uma plantação de 1,2 milhões de pés de cajueiro, cultura de sequeiro e de ciclo longo, dos quais esperava-se colher 50.000 toneladas de castanha na primeira safra, prevista para o início dos anos 1980. Com a sequência de cinco anos de seca, de 1978 a 1983, grande parte do cajueiro foi destruída, e a colheita alcançou pouco mais que 2,5 toneladas. A frustração com a fruticultura de sequeiro fez a MAISA direcionar a estratégia para a produção de frutas frescas de ciclo curto a partir de 1985, conduzindo a fruticultura irrigada para a liderança da economia exportadora do Rio Grande do Norte. A partir daí o modelo exógeno de crescimento agrícola estimulado por favoráveis incentivos de um Estado com crença na doutrina keynesiana de crescimento econômico, se fortaleceu no final da década de 1980 alcançando seu auge a partir da primeira metade da década de 1990. 
A competitividade da fruticultura irrigada do Rio Grande do Norte teve influência direta do pioneirismo da empresa MAISA, razão pela qual a sua importância para região é lembrada constantemente em estudos acadêmicos e técnicos relacionados à produção agrícola no semiárido nordestino. No entanto, o contexto socioeconômico de crise econômica levou à falência da empresa MAISA, e a demissão em massa dos empregados das empresas de todo Grupo MAISA sem o devido pagamento das verbas trabalhistas, alinhada a improdutividade de uma grande propriedade rural demais de 20.000 hectares, além da pressão dos movimentos sociais pela reforma agrária ${ }^{4}$ bastante aguardada no período de 2003 a 2006, resultou numa intervenção estatal através da desapropriação das terras. O fim das atividades da MAISA foi resultante, entre outros motivos, da ocorrência de uma reestruturação agrícola que reconfigurou o espaço rural, através de uma intensa mobilidade de capital. E nesse momento, a atuação estatal foi para o atendimento de segmentos rurais marginalizados, com estratégias relacionadas especialmente com a agricultura familiar, como a reforma agrária e o PRONAF (NUNES e SCHNEIDER, 2012).

Inicialmente, a empresa MAISA era vinculada ao grupo empresarial liderado pela Empresa Industrial Técnica (EIT), indústria da construção civil fundada em 1951 e que já figurou como uma das maiores do Brasil. De acordo com Nunes e Schneider (2013), o projeto MAISA foi ampliado e diversificado com a criação de empresas relacionadas ao ramo agropecuário e, consequentemente, o novo conglomerado foi configurado em um grupo econômico específico. Neste arranjo, conforme Nunes e Schneider (2013), tinha como holding a MAISA Participações, e como destaques a própria Mossoró Agroindustrial S.A. com a produção de frutas e a Maisa Indústria e Comércio S/A com a agroindústria de polpas, sucos e o processamento de castanhas de caju. Além da grande extensão territorial da propriedade rural, com mais de 20.000 hectares com poços profundos, packing houses e estradas vicinais internas, a infraestrutura física do complexo MAISA era composta por fábrica de sucos, fábrica de processamento de castanhas de caju, fábrica de produção de tubos para irrigação, aeroporto privado, centro administrativo, laboratórios de pesquisa. Segundo Nunes e Schneider (2013), nas margens da BR 304 foi construída uma vila residencial com

\footnotetext{
${ }^{4}$ Desde a sua concepção o assentamento é caracterizado pela multiplicidade de movimentos sociais que representam os assentados, especialmente como ocorreu à divisão territorial das agrovilas. Segundo o Centro Nacional de Pesquisas e Conservação de Cavernas do Rio Grande do Norte - CECAV/RN (2011), aos agricultores sem terras de Mossoró foram destinados 5.603 ha (agrovilas Angicos, Paulo Freire, APAMA e Poço 10), ao Movimento dos Sem Terra (MST), 5.269 ha (agrovilas Montana, Pomar e Real) e aos sem terras de Baraúna 4.806 ha (agrovilas Vila Nova I, II e III).
} 
600 casas para as famílias dos empregados, com escola, centro comunitário, creche, posto de saúde, posto policial, áreas de lazer, pontos comerciais, rede de energia elétrica e sistemas de abastecimento de água e de saneamento.

Quando o cenário direcionou para o inevitável encerramento das atividades e falência, o grupo MAISA criou a Companhia Nacional de Frutas (CNF), envolvendo o Banco Fator e o Banco Nacional de Desenvolvimento Econômico e Social (BNDES) num processo de fusão de empresas de destaque no segmento agropecuário que apresentavam dificuldades financeiras. A CNF seria constituída pelo grupo MAISA, a empresa Fruit Fort de Petrolina/PE e as companhias potiguares Fazenda São João e Frunorte, com um capital girando em torno de $\mathrm{R} \$ 350.000 .000,00$. Como representava uma operação de grande porte e com diversos interessados, incluindo bancos credores, ocorreram divergências na divisão de ações preferenciais, e a constituição da CNF não se concretizou (SÁ, 2003).

A fábrica de processamento de castanhas de caju encerrou as suas atividades no final da década de 1990, podendo representar o primeiro ciclo de declínio do grupo empresarial. A fábrica de polpa de frutas e de sucos da MAISA e a produção de frutas foram destaques no âmbito da fruticultura brasileira, mas devido ao crescente endividamento financeiro encerram as atividades no ano de 2002. Nas suas fases mais intensas da atividade econômica, a MAISA empregava em torno de 6 mil pessoas e alcançava o faturamento de U\$ 60 milhões de dólares, exportando cerca de 70\% de toda sua produção (NUNES; SCHNEIDER, 2013).

O encerramento das atividades da empresa Mossoró Agroindustrial S.A. (MAISA) em junho de 2002 resultou na chamada "improdutividade da sua propriedade rural", ocorrendo no dia 3 de dezembro de $2003^{5}$ a sua desapropriação para fins de reforma agrária. Esse é o momento que se dá origem ao Projeto de Assentamento denominado de Eldorado dos Carajás II, conhecido atualmente "Assentamento MAISA", uma área que faz fronteira com os municípios de Mossoró e Baraúna, no Rio Grande do Norte. O Assentamento é considerado um dos maiores do Brasil, com 19.709,0984 hectares, tendo o governo federal investido R\$ 8.909.077,48 (Oito milhões, novecentos e nove mil, setenta e sete reais e quarenta e oito centavos), na aquisição e estruturação do imóvel (SÁ, 2003).

Para Delgado (2012), na década de 1980, ganharam força as críticas ao processo de modernização da agricultura que foi implantada no Brasil a partir dos anos de 1970 e

\footnotetext{
${ }^{5}$ Decreto de 3 de dez. 2003. Disponível em: http://www.planalto.gov.br/ccivil_03/DNN/2003/Dnn10057.htm. 
fortemente baseada em modelos agrícolas especializados e exógenos. Os questionamentos eram sustentados nos seus impactos negativos, no que diz respeito às esferas ambientais, culturais, econômicas e sociais. A base dos questionamentos não era a democratização da revolução verde, mas a adoção das denominadas "tecnologias alternativas" visando um novo processo de desenvolvimento mais endógeno, com a minimização dos impactos negativos e com a inclusão dos agricultores familiares nas políticas de desenvolvimento e, consequentemente, das populações do meio rural. A nova perspectiva, a da consolidação de uma dinâmica de desenvolvimento rural, era construída no sentido de contestação da modernização agrícola e direcionava a atenção para a afirmação da agricultura familiar como segmento importante para a economia brasileira. Além disso, havia toda uma preocupação com a diversificação da agricultura familiar e a preservação ambiental fazendo surgir, assim, o alinhamento com a concepção do "desenvolvimento sustentável”.

\section{A DINÂMICA DE DESENVOLVIMENTO RURAL E A DIVERSIFICAÇÃO DA AGRICULTURA FAMILIAR}

Com a finalidade de compreender a dinâmica de desenvolvimento rural, se faz necessária a apresentação de perspectivas que tratam do desenvolvimento, como contribuição para o entendimento das referências teóricas acerca da relação desenvolvimento $\mathrm{x}$ crescimento econômico. De acordo com Souza (2005), os resultados oriundos das teorias de crescimento econômico, no sentido de fazer crescer o PIB de países por meio dos aumentos de produtividade, muitas vezes geram apenas o fenômeno do crescimento sem provocar alterações nas estruturas de distribuição da riqueza. Dessa forma, apenas aumenta o patrimônio dos ricos e mantêm a pobreza dos mais pobres, sem necessariamente reduzir as desigualdades. Cabe ressaltar que taxas de crescimento iguais de PIB tendem a camuflar, confundir e esconder variações na melhoria das condições de vida das pessoas e do seu Índice de Desenvolvimento Humano (IDH), índice divulgado desde o ano de 1993 pelo Programa das Nações Unidas para o Desenvolvimento (PNUD).

Determinados modelos de crescimento, os mais caracterizados como predatórios, podem gerar efeitos negativos, a exemplo da ampliação da fome e da insegurança alimentar, das desigualdades, da exclusão e da degradação ambiental e dos recursos naturais de países e regiões, apesar do crescimento ser indispensável para que ocorra o desenvolvimento. No 
entanto, a abundância de riqueza por ocasião do crescimento econômico do período do período pós Segunda Guerra mundial acontecia a partir da concentração geográfica em um desenvolvimento desigual. E a desigualdade gerada pelo crescimento econômico, desde os anos 1950 até no início do século XXI, recebem críticas de desenvolvimentistas (HIRSCHMAN, 1961; PERROUX, 1967; MYRDAL, 1972; e SEN, 2001), difundidas especialmente por estes expoentes internacionais. Estas contribuições com o desenvolvimento expõem uma das características da teoria de crescimento endógeno, quando da defesa da potencialidade do capital humano, e que devem ser consideradas as suas capacidades individuais como forma de alcance de maior liberdade, assim como dos níveis de produtividade e da melhoria das suas condições de vida.

Considerando o meio rural, as contribuições sobre o desenvolvimento rural (MARSDEN, 2003; SCHNEIDER, 2003; PLOEG; MARSDEN, 2008; McMICHAEL, 2013; PLOEG, 2018) são as que se colocam contrárias às conseqüências da modernização agrícola e dos seus modelos especializados e exógenos de crescimento. E essas consequências são a preocupação de autores que revelam a face não bem-sucedida dos modelos de crescimento da modernização agrícola, e mostram a capacidade questionável dos modelos exógenos de gerar retorno social. Dessa forma, a crença nas explicações exógenas tem se tornado cada vez menos convincente nos processos de formatação de políticas de desenvolvimento rural, especialmente para as regiões menos desenvolvidas e que ainda se encontram diversificadas..

Para Marsden (2003), a dinâmica de desenvolvimento rural necessita ser direcionada no sentido de difundir uma crença diferente e contrária das defendidas pelas explicações exógenas, assim como dar ênfase a abordagem territorial e endógena. Para este autor, temas relacionados à segurança alimentar devem ser considerados, tendo em vista que a maioria das organizações envolvidas com dinâmicas de desenvolvimento rural a partir dos anos 2000 buscavam incentivar ações com base na sustentabilidade.

Para Ploeg e Marsden (2008), o desenvolvimento rural representa um intenso processo engendrado por agricultores familiares que tem como ideia central a revitalização e a valorização do rural, bem como cada ator se posiciona e se relaciona na sociedade. Para estes autores, isso implica na necessidade de uma constante rearticulação e das atividades das redes que constituem e constroem as dinâmicas do desenvolvimento rural. Quanto a defesa de Ploeg (2018), este defende a dinâmica de desenvolvimento rural onde as políticas devem considerar a cultura local e a capacidade coletiva dos atores locais, e afirma ser um erro 
qualquer gestor ou planejador de políticas acreditar que a economia, seja de um país ou região, ser sustentada por um modelo baseado no gigantismo de empresas, quando em países e regiões subdesenvolvidas as grandes empresas são muito instáveis e vulneráveis, por serem dependentes de oscilações e fatores externos.

Para Nunes e Schneider (2013) e Ploeg (2018), a mudança na concepção do desenvolvimento rural com a defesa do desenvolvimento mais endógeno com menor dependência dos fatores exógenos, estimula as condições para tratar da diversificação da agricultura familiar, da valorização de sistemas agroalimentares locais, da sustentabilidade, da segurança alimentar e da construção de mercados. Essa concepção do desenvolvimento rural tem destacado autores, a exemplo de McMichael (2013), que chamam a atenção para regimes alimentares alternativos, em que o alimento entra como o novo elemento na centralidade da questão agrária. E esta contribuição do McMichael (2013), se coloca como adequada à dinâmica constituída pelo assentamento MAISA, no Rio Grande do Norte.

Para Schneider (2010b), fatores decisivos para legitimar o desenvolvimento rural são os seguintes: i) discussões em torno da agricultura familiar e de seu potencial como modelo social e econômico para a sociedade brasileira; ii) a crescente influência e ação do Estado no meio rural, através das políticas para a agricultura familiar como das ações relacionadas à reforma agrária, segurança alimentar, entre outras; iii) mudanças no âmbito político e ideológico (uma argumentação que visava mostrar as diferenças fundamentais entre o universo de produtores da agricultura brasileira); e iv) sustentabilidade ambiental.

Esses fatores apontados por McMichael (2013) e Schneider (2010b), vêm promovendo uma recente configuração em dinâmicas de desenvolvimento rural baseadas no desenvolvimento endógeno, em que a valorização de sistemas alimentares localizados desencadeiam uma dinamização territorial devido a organização coletiva, a agregação de valor e a construção de mercados no âmbito da agricultura familiar. Essa é a mais recente literatura nacional (MALUF; REIS, 2013; NIEDERLE; WESZ JUNIOR, 2016; GAZOLLA; SCHNEIDER, 2017; MARQUES, CONTERATO; SCHNEIDER, 2018), que tenta direcionar a dinâmica de desenvolvimento rural para contribuições sobre o sistema agroalimentar. As contribuições que que incluem a importância da produção de alimentos via sistemas alimentares localizados buscam compreender a importância dos mercados locais e regionais a partir do cada vez maior surgimento dos circuitos agroalimentares curtos. Essa é uma nova reformulação de dinâmicas regionais de desenvolvimento rural que são 
direcionadas para a valorização de regimes alimentares localizados, o vai na contramão das estratégias da modernização que vinculava o padrão tecnológico exógeno ao regime alimentar global dominado por corporações mundiais praticantes de circuitos longos.

Para Baiardi (2014) e Ploeg (2018), a relação do agricultor familiar com a terra é uma afirmação da relação homem-terra-natureza cada vez mais forte, sendo capaz de fazer com que o agricultor não encerre a atividade e se mude para a cidade em casos de instabilidades. Considerando os aspectos das ruralidades, conforme Schneider (2003), o modo de vida é influenciado por contextos que definem a melhor estratégia para viver dignamente no meio rural. Isso significa que o meio rural, a exemplo do assentamento MAISA, no Rio Grande do Norte, pode ser um ambiente dinâmico e que as atividades praticadas pelos agricultores familiares se tornem mais rentáveis a partir de estratégias de organização coletiva, agregação de valor e sua conexão com o meio urbano por meio da construção de mercados. Não se deve ignorar ou desconsiderar a capacidade coletiva dos atores para engendrar processos que venham dinamizar e construir uma promissora concepção de dinâmica de desenvolvimento rural a partir da agricultura familiar.

\section{METODOLOGIA}

De acordo com a metodologia foi utilizado o estudo de caso, sendo a unidade de análise a família vinculada à exploração ou não do lote de terra. A pesquisa foi caracterizada pela análise detalhada das agrovilas do Projeto de Assentamento MAISA, no Rio Grande do Norte. A implantação do Assentamento MAISA com capacidade para 1.150 famílias foi caracterizada pela sua distribuição populacional entre 10 agrovilas, sendo seis localizadas no Município de Mossoró (RN) e quatro no Município de Baraúna (RN). Além de atender a reivindicações de movimentos sociais e de demandas políticas, a distribuição espacial através de agrovilas foi utilizada como critério em virtude da extensão territorial da propriedade desapropriada, cuja área total é de 20.202 hectares. 
Figura 1: Mapa do Rio Grande do Norte e localização do Projeto de Assentamento MAISA

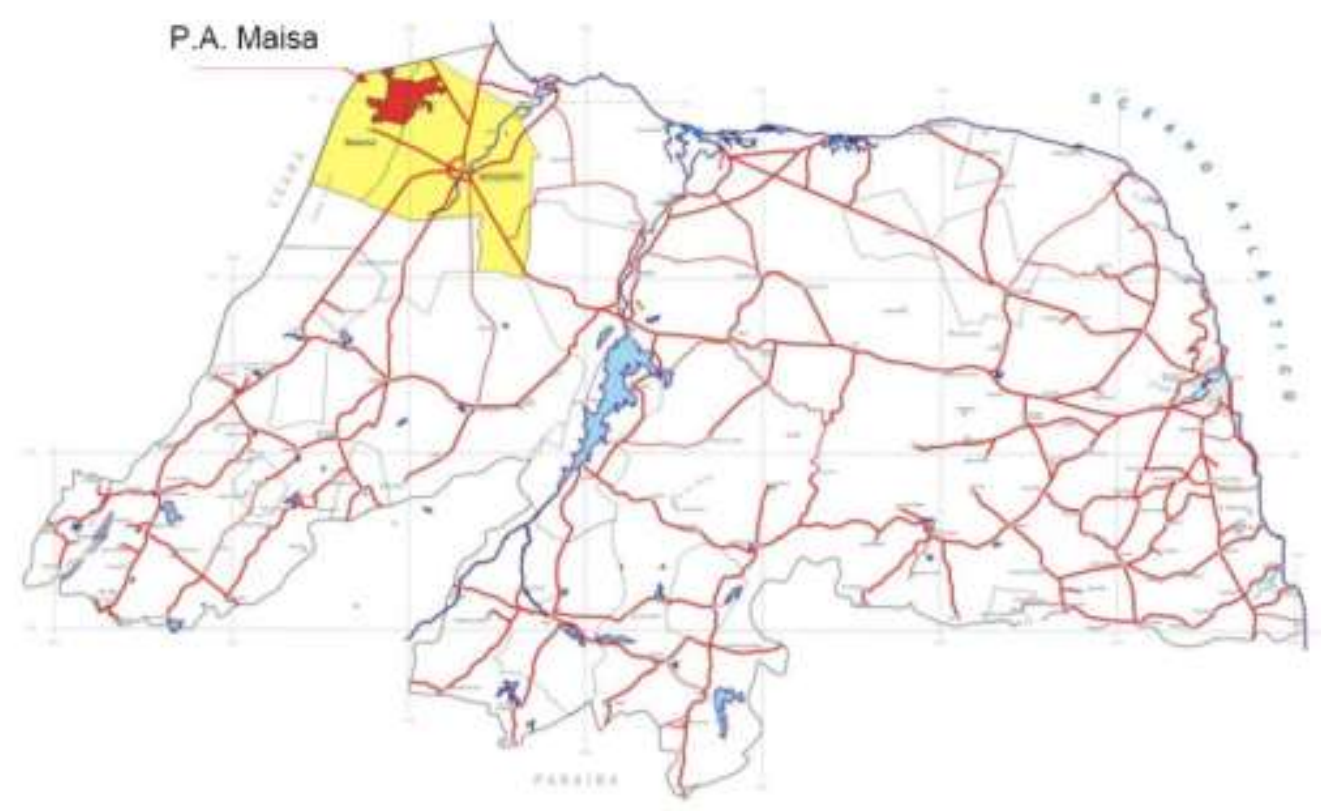

Fonte: CECAV/RN (2011)

Considerando a população da pesquisa (total de 1.150 famílias) o cálculo amostral adequado foi do tipo tamanho amostral para população finita, conforme fórmula abaixo (MARTINS E THEÓPHILO, 2009).

Onde:

$$
\mathrm{n}=\frac{Z^{2} * \mathrm{p} * \mathrm{q} * \mathrm{~N}}{\mathrm{~d}^{2}(\mathrm{~N}-1)+Z^{2} * \mathrm{p} * \mathrm{q}}
$$

$\mathrm{n}=$ tamanho da amostra aleatória simples a ser selecionada pela população.

$\mathrm{N}=$ tamanho da população.

$\mathrm{Z}=$ abscissa da normal padrão $(95 \%)$.

$\mathrm{p}=$ percentagem com a qual o fenômeno se verifica.

$q=$ percentagem complementar (1-p).

$\mathrm{d}=$ erro amostral.

Foi utilizado o nível de confiança de $95 \%$ e o erro amostral utilizado foi de $10 \%$ em virtude da natureza da pesquisa. A fórmula aplicada foi baseada na população do projeto de assentamento (Universo de 1.150 famílias) obtendo a amostra de 89 famílias de agricultores familiares do assentamento MAISA. Considerando a existência e distribuição espacial de dez agrovilas com quantidades populacionais e características diferentes, a amostra foi dividida de forma proporcional entre essas comunidades, conforme Tabela 1. 
Tabela 1 - Agrovilas com seus respectivos universos e tamanhos de amostra

\begin{tabular}{cccc}
\hline Agrovila & Município & Universo & $\begin{array}{c}\text { Tamanho da } \\
\text { amostra (n) }\end{array}$ \\
\hline Pomar & Mossoró & 110 & 9 \\
Paulo Freire & Mossoró & 100 & 8 \\
Poço 10 & Mossoró & 100 & 8 \\
Montana & Mossoró & 100 & 8 \\
Real & Mossoró & 80 & 6 \\
Apama & Mossoró & 183 & 14 \\
Vila Nova I & Baraúna & 116 & 9 \\
Vila Nova II & Baraúna & 119 & 9 \\
Vila Nova III & Baraúna & 120 & 9 \\
Angicos & Baraúna & 122 & 9 \\
\hline
\end{tabular}

Fonte: Elaboração dos autores, 2014.

Os dados primários foram coletados perante as famílias do Assentamento MAISA, com a aplicação de questionários estruturados no ano de 2014, obtendo informações sobre o último ano agrícola, ou seja, o ano de 2013. Foram aplicados 89 questionários com famílias dos assentados distribuídas nas 10 agrovilas do assentamento, e realizadas 10 entrevistas semiestruturadas com cada gestor das dez associações. Por fim, foram utilizados dados secundários emitidos por órgãos públicos para a análise da dinâmica da agricultura familiar. O tratamento dos dados se deu por meio das técnicas qualitativas e quantitativas, que ajudaram numa análise mais detalhada e aprofundada da dinâmica da agricultura familiar.

\section{RESULTADOS E DISCUSSÃO}

\section{A dinÂmica da Agricultura FAmiliar no ASSEntamento MAISA, Rio Grande do NORTE}

O assentamento MAISA se caracteriza uma importante experiência de agricultura familiar, e vem se constituindo numa destacada dinâmica de desenvolvimento rural do Rio Grande do Norte. E o que chama a atenção para essa dinâmica, é o fato da área em que foi instalado o assentamento ter sido, no período de 1968 a 2003, de uma das maiores e mais modernas empresas voltadas para a produção e exportação de frutas irrigadas do país. Os resultados da pesquisa mostrados daqui em diante, mostram um pouco dessa dinâmica que antes foi a empresa MAISA, baseada num modelo exógeno e de crescimento, e que atualmente é o assentamento MAISA baseado na agricultura familiar e com o desafio de se viabilizar no âmbito da reforma agrária como dinâmica de desenvolvimento rural. 
Quanto à produção vegetal, a área total plantada foi de 288,66 ha e uma produção de 2.377.688kg, conforme mostra a tabela 2. Destacam-se em relação à área plantada as culturas do feijão $(28,16 \%)$, milho (19,54\%), melão $(18,88 \%)$ e melancia (15,76\%). Contudo, quando se analisa essas culturas em relação à produção total vegetal, o feijão e o milho representam, respectivamente, $1,24 \%$ e $0,12 \%$. A produção do feijão foi realizada por 31,46\% das famílias entrevistadas, e o milho por $13,48 \%$. Já o melão é responsável por $65,82 \%$ da produção total e produzido por apenas $5,62 \%$ das famílias. A produção de melancia é equivalente a $31 \%$ do total e concentrada em 7,86\% das famílias assentadas. A acerola teve uma área plantada de 21 ha, a produção de $27.250 \mathrm{~kg}$ através de $8,99 \%$ das famílias, a partir de um pomar preexistente da empresa MAISA localizado na Vila Pomar.

Tabela 2 - Produção vegetal do Assentamento MAISA para autoconsumo e comercialização.

\begin{tabular}{lccccc}
\hline Produto & $\begin{array}{c}\text { Área } \\
\text { plantada } \\
\text { total (ha) }\end{array}$ & $\begin{array}{c}\text { Produção } \\
\text { total } \\
(\mathbf{k g})\end{array}$ & $\begin{array}{c}\text { Quantidade } \\
\text { comercializada } \\
\mathbf{( k g )}\end{array}$ & $\begin{array}{c}\text { Quantidade } \\
\text { consumida pela } \\
\text { família (kg) }\end{array}$ & $\begin{array}{c}\text { Quantidade } \\
\text { utilizada na } \\
\text { propriedade } \\
\text { (kg) }\end{array}$ \\
\hline Batata doce & 0,5 & 2.500 & 2.500 & - & - \\
Fava & 12,8 & - & - & - & - \\
Feijão & 81,3 & 29.593 & 23.878 & 5.555 & 160 \\
Mandioca & 3,65 & 9.030 & 6.000 & 30 & 3.000 \\
Milho & 56,4 & 2.930 & 110 & 1.680 & 1.140 \\
Acerola (Kg) & 21 & 27.250 & 27.250 & - & - \\
Caju & 10 & 200 & 200 & - & - \\
Castanha & de & 575 & 575 & - & - \\
caju & & 110 & 100 & 10 & - \\
Coco (unid.) & 0,0072 & - & - & - & - \\
Manga & 1 & -537.000 & 737.000 & - & - \\
Melancia & 45,5 & 7360 & - & - \\
Melão & 54,5 & 1.565 .000 & 1.565 .000 & - & - \\
Pimentão & 1 & 800 & 800 & - & $\mathbf{4 . 3 0 0}$ \\
Tomate & 1 & 2.700 & 2.700 & $\mathbf{7 . 2 7 5}$ & \\
\hline Total & $\mathbf{2 8 8 , 6 6}$ & $\mathbf{2 . 3 7 7 . 6 8 8}$ & $\mathbf{2 . 3 6 6 . 1 1 3}$ & & - \\
\hline
\end{tabular}

Fonte: Pesquisa de campo, 2014. Elaboração dos autores.

No assentamento MAISA, conforme mostrado na tabela acima, a decisão foi para a produção vegetal caracterizada pelas culturas tradicionais mais voltadas para o autoconsumo, e por culturas mais modernas e comerciais voltadas para o mercado. Os dados apresentam um desempenho das culturas tradicionais, a exemplo do feijão, do milho e da mandioca, bem abaixo das culturas comerciais e de elevado desempenho lideradas pelo melão e pela melancia. Cabe ressaltar que a experiência adquirida por alguns assentados, quando 
empregados da empresa MAISA, se configura um aprendizado determinante para desenvolver culturas comerciais e alcançar um bom desempenho em culturas exigentes em conhecimento, a exemplo do melão e da melancia.

Os dados da pesquisa mostram que as culturas do feijão e do milho apresentam a maior quantidade para o autoconsumo da família e da propriedade, se apresentando como parte importante na constituição da renda familiar. Já as culturas do melão, melancia e acerola foram totalmente direcionadas para a comercialização. O Gráfico 1 mostra que 69,66\% das famílias responderam que plantaram, culturas de autoconsumo e comerciais, sendo que 21,34\% das famílias não obtiveram produção, isso em virtude de motivos já apontados, a exemplo da seca e de alguns assentados decidirem ser e se manter empregados em empresas agrícolas do que explorar e produzir na sua terra.

Gráfico 1 - Proporção das famílias que plantaram e das que não plantaram, e o seu resultado.

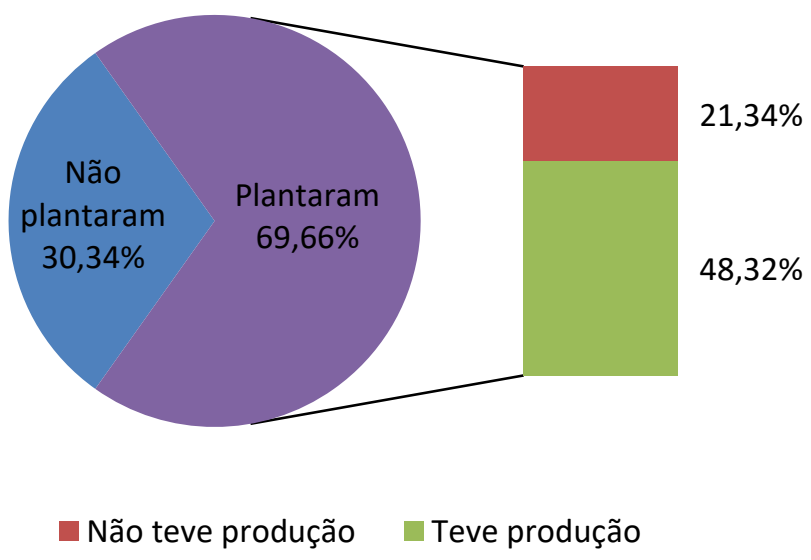

Fonte: Pesquisa de campo, 2014. Elaboração dos autores.

Conforme Nunes (2009), o fenômeno da seca para a região semiárida representa um desafio para a agricultura de sequeiro, e o desempenho das culturas do feijão e do milho afirmam, quando comparado o percentual de famílias que plantaram com os que tiveram produção. Das famílias entrevistadas, $58,42 \%$ responderam ter plantado feijão e destas somente $31,5 \%$ tiveram produção, enquanto a cultura do milho foi cultivada por $31,46 \%$ das famílias e apenas $13,5 \%$ delas obtiveram produção. O percentual que apresentou produção teve a produtividade abaixo do planejado, e a justificativa dos agricultores familiares em relação à produção reduzida é sempre baseada na seca. 
A situação que a pesquisa revelou para culturas tradicionais e de sequeiro, como a do feijão e do milho, não foi a mesma identificada para as culturas comerciais, a exemplo do melão e da melancia. As culturas comerciais utilizam sistemas modernos de irrigação e praticam técnicas agrícolas consolidadas. Somados, os grupos que não plantaram e os que perderam a produção totalizam $51,68 \%$ das famílias entrevistadas, sendo mais da metade os que não alcançaram renda através da atividade agrícola. No assentamento MAISA, a pesquisa identificou que nem todas as famílias produzem culturas de autoconsumo e culturas comerciais concomitantemente, pois nem todos os agricultores familiares que plantam apenas milho e feijão possuem condições para investir em sistemas modernos de irrigação, contratar força de trabalho e adquirir insumos para produzir melão e melancia.

Com relação ao principal destino da produção vegetal, os dados da pesquisa mostram que $14,62 \%$ das famílias responderam que foi para o autoconsumo delas e da propriedade, e de $33,71 \%$ responderam que foi para a comercialização, como mostra o gráfico 2. Cabe destacar que 51,68\% das famílias entrevistadas responderam não terem produziram nada, e os principais motivos por não terem obtido nenhuma produção no ano agrícola analisado foram dois: 1) o de parte dos agricultores serem empregados em empresas agrícolas e não explorarem os seus lotes de terra; e 2) devido ao intenso período de seca que influenciou para a queda e perda total das plantações. Assim, das 33,71\% famílias que comercializaram sua produção vegetal, 7,87\% informaram como destino a venda direta, 1,12\% destinaram para mercados institucionais (PAA, PNAE, etc.), 23,60\% para atravessadores e apenas 1,12\% para agroindústrias ou empresas. Para Silva et al. (2017), mercados institucionais são mecanismos importantes de inclusão econômica e da redução da desigualdade, e uma potencialidade para a intervenção estatal reduzir a ação dos atravessadores, ampliar a produção e estimular a agroindústria no assentamento MAISA. 
Gráfico 2 - Principal destino da produção vegetal da família

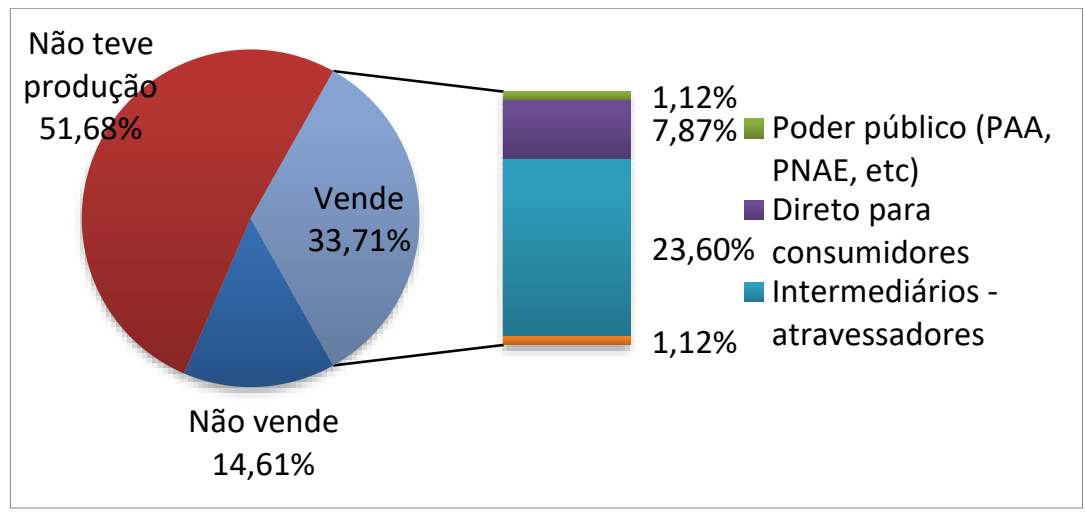

Fonte: Pesquisa de campo, 2014. Elaboração dos autores.

Deve-se salientar que os $51,68 \%$ das famílias entrevistadas que não obtiveram produção agrícola, parte delas informaram que a ausência da renda agropecuária foi compensada por rendas rurais não agrícolas, especialmente obtidas como empregados em empresas agrícolas, empregos domésticos em cidades como Mossoró, além das rendas oriundas de aposentadorias, bolsa família, e de programas, como o Programa de Microcrédito Rural Orientado (AGROAMIGO) e do Garantia-Safra. A pesquisa revelou, ainda, que no assentamento MAISA a maioria das famílias utiliza tecnologias relativamente arcaicas e de baixo custo, de trabalho manual, com necessidade de atualização tecnológica.

E a identificação de um padrão técnico tradicional, de baixo custo e de pouco desempenho por parte das famílias do assentamento MAISA é refletido na quase inexistência de Assistência Técnica e Extensão Rural (ATER). Como mostrado no gráfico 3, quando perguntados apenas 3,37\% das famílias entrevistadas responderam que receberam assistência técnica, enquanto 96,63\% não foram atendidas por esse serviço. 
Gráfico 3 - Famílias rurais com acesso à Assistência Técnica e Extensão Rural (ATER)

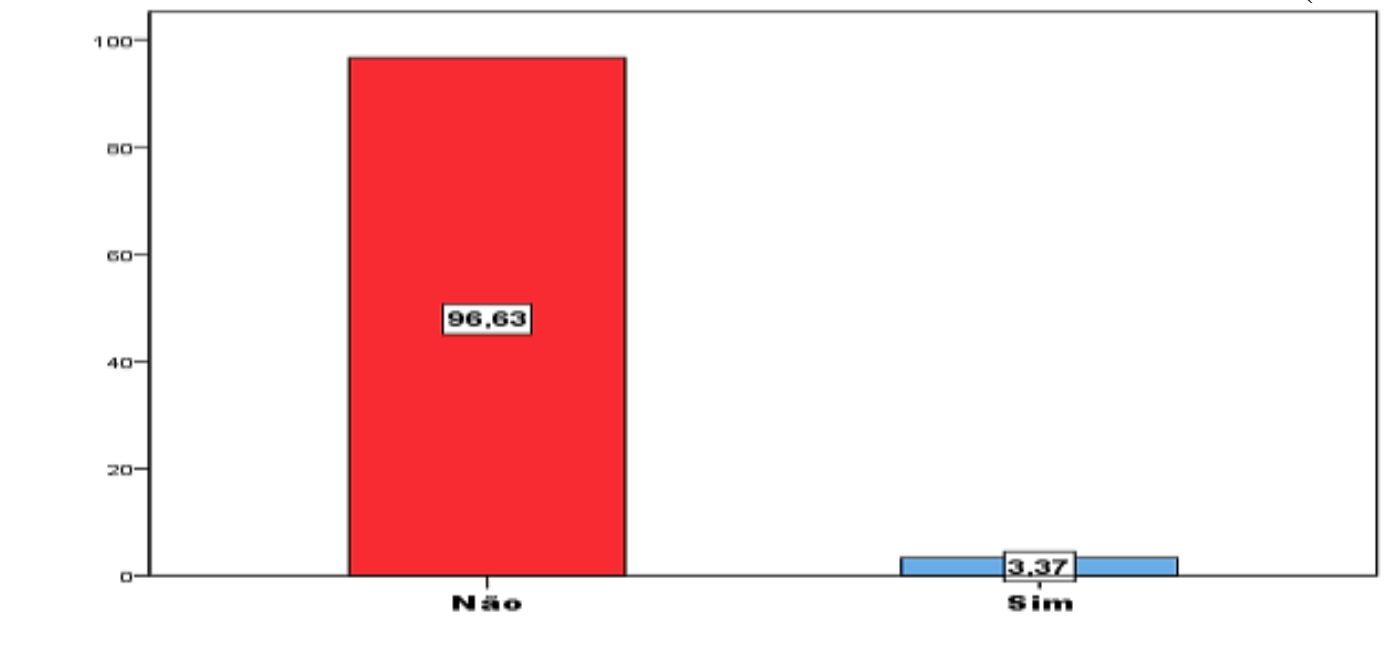

Fonte: Pesquisa de campo, 2014. Elaboração dos autores.

As famílias que foram assistidas por serviços de ATER no assentamento MAISA estão distribuídas da seguinte forma: 1,12\% através do INCRA, 1,12\% da EMATER e 1,12\% de empresas integradoras. Segundo Nunes et al. (2020), o fortalecimento da agricultura familiar acontece com serviços contínuos de ATER, organização coletiva e acesso ao crédito. Além de identificar necessidades e desenvolver potencialidades, a ATER é fundamental para o acesso dos agricultores familiares às políticas públicas e aos mercados, entre eles os institucionais. Para Nunes et al. (2020), o agricultor familiar tem a necessidade de crédito e de formas de comercialização, sendo que o aproveitamento eficiente dessas oportunidades é maximizado a partir de contínuos serviços de ATER.

No assentamento MAISA, a pesquisa identificou o associativismo comunitário, porém com suas atividades voltadas mais para a gestão da infraestrutura das agrovilas. As atividades das associações do assentamento MAISA conciliam com Oliveira (2010) e Nunes e Schneider (2012), ou seja, que a sua criação foi exigência das agências públicas de fomento, mais para acessar recursos de políticas, que para a organização da produção agropecuária. A identificação por parte da pesquisa da baixa produtividade e ausência de produção agrícola apontam para a existência de outras fontes de renda no assentamento MAISA, que fazem parte da composição de renda dos agricultores familiares assentados, como uma estratégia definida por Schneider (2003) como pluriatividade ${ }^{6}$.

\footnotetext{
${ }^{6}$ Para uma definição da pluriatividade, Schneider (2003) coloca que esta estratégia ocorre a partir da combinação do exercício (por parte de membros de uma mesma família) de uma ou mais atividades não-agrícolas ou atividade ligada ao setor agrícola, mas fora da propriedade, seja na forma de prestação de serviços ou assalariamento, sendo estas atividades exercidas por pelo menos um membro da família.
} 
Destes, $18 \%$ dos responsáveis pela família foram identificados em atividades rurais não agrícolas e 36\% em atividades rurais agrícolas. Em relação ao cônjuge, 14,5\% laboraram fora da propriedade, com 7,8\% em atividades não agrícolas e 6,7\% em agrícolas, e os demais membros tiveram 2,2\% que trabalharam em atividades agrícolas. O detalhamento das famílias com membros familiares em atividades não agrícolas tem como destaques o serviço público por 31,3\% dos responsáveis das famílias, e 44,4\% dos cônjuges, conforme tabela 3.

Tabela 3 - Distribuição das atividades não agrícolas por setor realizadas em 2013

\begin{tabular}{ccc}
\hline Setor & Responsável (\%) & Cônjuge (\%) \\
\hline Indústrias & 18,8 & 11,1 \\
Construção Civil & 18,8 & 11,1 \\
Serviço Público & 31,3 & 44,4 \\
Serviço Pessoal & 12,5 & - \\
Comércio & - & 11,1 \\
Outros & 18,8 & 22,2 \\
\hline Total & $\mathbf{1 0 0 , 0}$ & $\mathbf{1 0 0 , 0}$ \\
\hline
\end{tabular}

Fonte: Pesquisa de campo, 2014. Elaboração dos autores.

A variedade, ou diversificação de atividades não agrícolas identificadas no assentamento MAISA alinha-se com a afirmação de Kageyama (2004), de que o rural não é sinônimo apenas de agrícola, e que as atividades não agrícolas não constituem o abandono da área rural pelos produtores, mesmo que a produção seja destinada mais para o autoconsumo. E, muitas vezes, são políticas públicas, a exemplo do crédito, dos serviços de ATER, da organização coletiva, da qualificação e do acesso a mercados, entre outras, que definem a dinâmica do meio rural influenciando da composição da renda familiar.

Com relação ao acesso ao crédito, a seca que atingiu a região Nordeste a partir de 2011 resultou na concessão de uma linha especial para os agricultores familiares enquadrados no PRONAF B (BCB, 2014), onde 69,67\% das famílias entrevistadas receberam esse crédito com a finalidade de investimento, conforme Gráfico 4. No entanto, a quantidade de famílias que não tiveram acesso ao crédito foi de $29,21 \%$, o que requer atenção para a necessidades financeiras para dificuldades estruturais provocadas pelas condições climáticas. 
Gráfico 4 - Obteve financiamento ou empréstimo com a respectiva fonte

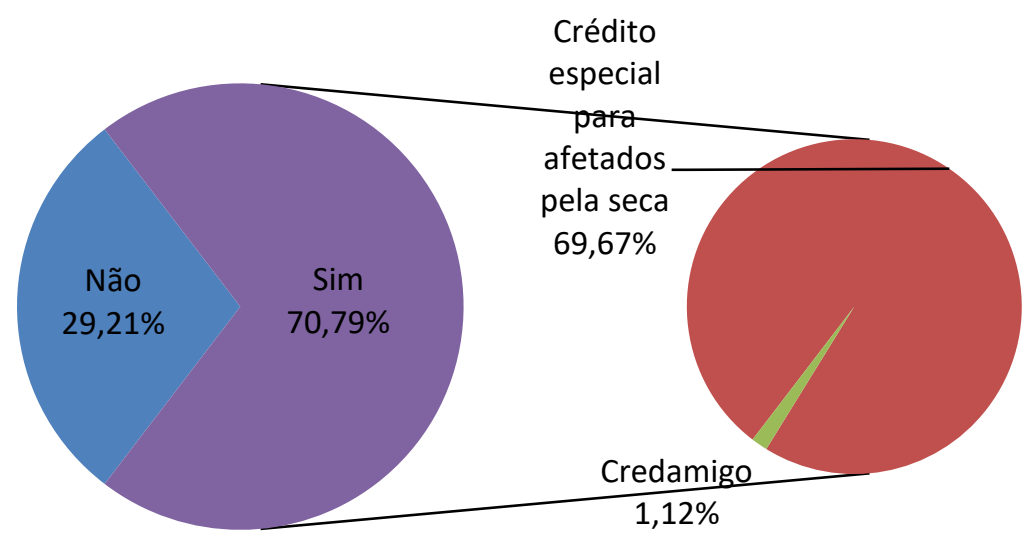

Fonte: Pesquisa de campo, 2014. Elaboração dos autores.

O AGROAMIGO foi percebido por uma família assentada $(1,12 \%)$ no valor de R\$ 538,00 que utilizou o crédito para abertura de uma lanchonete, na tentativa de diversificação da renda familiar. O crédito especial para afetados pela seca apresentou a média de $\mathrm{R} \$$ 11.457,42, valor próximo ao limite máximo de empréstimo dessa linha de financiamento que era de $\mathrm{R} \$ 12.000,00$.

Quanto às questões relacionadas à ruralidade, a pesquisa identificou que o grau de satisfação das famílias em relação às atividades agrícolas (trabalho e produção) e ao meio rural (espaço e a comunidade) é uma informação importância para entender as representações dos agricultores sobre a ruralidade, e a tabela 4 apresenta o grau de satisfação das famílias em relação à atividade agrícola e ao meio rural. Quanto à atividade agrícola, a predominância foi de satisfação (54,5\% satisfeitos e 14,8\% muito satisfeitos), apresentando 18,2\% como insatisfeitos e 12,5\% que não sabe/não respondeu. Esse contexto de avaliação positiva é maximizado pelo grau de satisfação em relação ao meio rural que obteve com a soma dos satisfeitos e muitos satisfeitos o percentual de $82 \%$, com $12,4 \%$ das famílias insatisfeitas e $5,6 \%$ que não sabe/não respondeu. 
Tabela 4 - Grau de satisfação dos produtores do Projeto de Assentamento e de sua família em relação às atividades agrícola e ao meio rural

\begin{tabular}{lcc}
\hline Avaliação & Atividade agrícola (\%) & Meio rural (\%) \\
\hline Muito satisfeito & 14,8 & 25,8 \\
Insatisfeito & 18,2 & 12,4 \\
Satisfeito & 54,5 & 56,2 \\
Não sabe/não respondeu & 12,5 & 5,6 \\
\hline Total & $\mathbf{1 0 0}$ & $\mathbf{1 0 0}$ \\
\hline
\end{tabular}

Fonte: Pesquisa de campo, 2014. Elaboração dos autores.

A partir da constatação da avaliação positiva em relação às atividades agrícolas e ao ambiente/comunidade é coerente a análise do que a família mais valoriza no meio rural. A tranquilidade foi à resposta de $64 \%$ das famílias e foi citado por $13,4 \%$ das famílias o trabalho na agricultura e a importância de produzir alimento, conforme tabela 5. Nesse caso, observase que a preferência por parte das famílias entrevistadas pelo aspecto tranquilidade superou os aspectos relacionados à atividade agrícola.

Tabela 5 - Valorização da família no meio rural ou no espaço rural

\begin{tabular}{|c|c|}
\hline Elemento & $\%$ \\
\hline A paisagem & 3,4 \\
\hline O trabalho na agricultura e a importância de produzir alimentos & 13,5 \\
\hline Os animais e as plantas & 12,4 \\
\hline A tranquilidade & 64,0 \\
\hline Vizinhos/comunidade em que vive & 6,7 \\
\hline Total & 100,0 \\
\hline
\end{tabular}

Fonte: Pesquisa de campo, 2014. Elaboração dos autores.

A migração do campo para a cidade é um tema bastante discutido na análise do processo de desenvolvimento, pois envolve possíveis efeitos negativos que extrapolam o ambiente rural e pode gerar a transferência de problemas sociais para o meio urbano. No projeto de assentamento MAISA, a predominância é pela não vontade de migração para a cidade pelos membros familiares $(74,46 \%)$, sendo que $22,47 \%$ apresentam o desejo de sair do ambiente rural e 1,12\% não souberam ou não responderam. Inclusive, o resultado negativo em relação à migração para a cidade, confirma a relação lúdica do produtor familiar com a terra conforme citado por Baiardi (2014). Para esse autor, muitas vezes, as razões ultrapassam os aspectos econômicos e sociais, resultando que a relação homem-terra-natureza seja capaz 
de fazer com que o agricultor não encerre a atividade e não migre para a cidade em casos de instabilidades ou adversidades, a exemplo da seca.

Em relação às famílias que desejam migrar para a cidade, apesar de constituir a minoria, a análise detalhada das razões para a migração é um parâmetro que pode subsidiar as políticas públicas e, assim, amenizar as suas consequências negativas. A Tabela 6 apresenta como principais motivos para a migração para a cidade a crença que o salário da cidade seria maior $(5,62 \%)$, o não interesse na atividade rural $(3,37 \%)$ e para estudar $(3,37 \%)$ que somadas essas opções representa mais da metade das famílias que possuem membros que desejam mudar para o ambiente urbano.

\section{Tabela 6 - Motivos para a migração das famílias que gostariam de mudar para cidade}

\begin{tabular}{lc}
\hline Motivo para a mudança para a cidade & $\mathbf{\%}$ \\
\hline Acredita que o salário da cidade será maior & 5,62 \\
Pouco trabalho no campo & 1,12 \\
Não tem interesse na atividade rural & 3,37 \\
É possível trabalhar no estabelecimento mesmo morando na cidade & 2,25 \\
Para estudar & 3,37 \\
Para tratamento de saúde & 1,12 \\
Para gozar da aposentadoria & 1,12 \\
Pouco trabalho no campo e para estudar & 1,12 \\
Acredita que o salário da cidade será maior, pouco trabalho no campo e para estudar. & 1,12 \\
Outros motivos & 2,26 \\
\hline Total dos que gostariam mudar para cidade & $\mathbf{2 2 , 4 7}$ \\
\hline
\end{tabular}
Fonte: Pesquisa de campo, 2014. Elaboração dos autores.

Para complementar a análise do grau de satisfação em relação à propriedade, as famílias assentadas foram questionadas sobre migração para outro lugar no campo, obtendo o percentual de $95,51 \%$ que afirmaram que não gostaria de mudar para outro lugar no campo e 4,49\% responderam que desejam migrar para outro lugar no campo. $\mathrm{O}$ local da propriedade apresenta baixo grau de insatisfação, tendo como pressuposto que as famílias não visualizam a localização do assentamento como entrave para o seu desenvolvimento. 


\section{CONSIDERAÇÕES FINAIS}

Considerando a interpretação e explicação das referências teóricas de crescimento versus desenvolvimento econômico, percebe-se dois momentos da análise: 1) o da empresa MAISA, exemplo de empreendimento de sucesso e de inspiração, por praticar uma agricultura capitalista moderna e baseada em modelos de crescimento econômico com explicações exógenas; e 2) o do assentamento MAISA, que é colocado diante do desafio de construção de uma trajetória com estratégias mais endógenas, no sentido de alcançar a viabilidade e o status de dinâmica de desenvolvimento rural através da agricultura familiar.

A baixa produtividade ou improdutividade agropecuária da maioria das famílias é minimizada estrategicamente pela complementação da renda familiar através do emprego de parte dos assentados em empresas agrícolas da região, e do acesso a políticas de assistência social, com destaques para a aposentadoria ou pensão, garantia safra e o programa bolsa família acessadas, respectivamente, por 44\%, 25,8\% e 42,7\% das famílias assentadas. Mas esse tipo de intervenção estatal meramente assistencialista não contribui para a dinamização e viabilidade econômica do assentamento MAISA. A pesquisa constatou que o combate à pobreza rural não acontece apenas através da disponibilidade de terras, sendo necessário obter a produtividade, ou seja, são imprescindíveis no âmbito da reforma agrária estratégias que abordem a capacidade e a competitividade dos assentados.

Os mercados institucionais (PAA e PNAE) constituem o resultado de uma grande pressão de grupos representantes da agricultura familiar por construção de mercados e pelo acesso a canais de comercialização que efetivamente promova a inclusão mercadológica dos agricultores familiares. O inexpressível acesso aos mercados institucionais representados pelo PAA e pelo PNAE, por apenas 1,12\% das famílias, é agravado pela produção existente de forma concentrada em poucas famílias de agricultores e com a venda com destino predominante nos atravessadores, mantendo as famílias cada vez mais limitadas para construir e manter outros mercados locais e regionais, a exemplo dos circuitos e/ou cadeias curtas. É preciso e urgente a implantação de estratégias capazes de quebrar o círculo vicioso da reprodução do papel de empregados de parte dos agricultores assentados, como faziam quando empregados da empresa MAISA, e dotá-los de mecanismos de estrutura e capacitação voltados para o empreendedorismo. Muitos agricultores externaram sentir falta do estímulo à organização coletiva, especialmente da criação de cooperativa, para que 
pudessem organizar e gerir melhor a produção, beneficiar para agregar valor e construir uma central de comercialização para construir mercados.

O Programa Nacional de Fortalecimento da Agricultura Familiar (PRONAF) é outra ação governamental resultante de reinvindicações sociais, políticas e acadêmicas, sendo a primeira linha exclusiva de crédito direcionada para a agricultura familiar, visando o custeio e o investimento nas atividades produtivas. A sua importância pode ser representada pela legitimação da agricultura familiar como categoria social pelo Estado brasileiro. No ano da pesquisa, nenhuma família do assentamento MAISA teve acesso ao crédito através do PRONAF, e teve a situação creditícia amenizada pela liberação de uma linha de crédito especial para as regiões afetadas pela seca.

A ausência de serviços de ATER no assentamento MAISA torna a situação dos agricultores familiares ainda mais difícil em virtude de se constituir uma área de intervenção estatal sem a devida atuação do Estado com políticas que possibilitem apoio e orientação no desenvolvimento das atividades produtivas. Considerando que o assentamento MAISA representa uma dinâmica de desenvolvimento rural que surge no lugar de uma grande empresa baseada em um modelo moderno de crescimento, existe um claro desafio de tornar viável essa experiência da agricultura familiar. E os serviços de ATER deveriam estar diretamente relacionados, entre outras coisas, com uma consolidada estrutura de organização coletiva, especialmente cooperativa, com o acesso qualificado ao crédito e com estratégias de agregação de valor (agroindústria) e com a inserção em mercados, inclusive o institucional. A tecnologia tem que ser adequada a realidade produtiva dos agricultores familiares e com a sua operacionalização ocorrendo de forma contínua e correta, sendo os serviços de ATER elementos chave para o atendimento desses requisitos. Inclusive, a tecnologia predominante no assentamento MAISA é tradicional e de baixo custo, se apresentando com pouco rendimento devido ao uso manual, resultando em reflexos negativos na produtividade.

As formas de organização coletiva identificadas no assentamento MAISA são caracterizadas pelo associativismo comunitário voltado para o atendimento de serviços na administração da infraestrutura das agrovilas. As atividades operacionais e gerenciais agropecuárias são executadas por cada família de forma individual e as associações não realizam ações relacionadas com o sistema produtivo, não reduzindo as dificuldades administrativas e operacionais das propriedades. Apesar do contexto adverso em termos 
produtivos, climáticas e de acesso a políticas especificas da agricultura familiar, as representações dos agricultores sobre a ruralidade e seu futuro são caracterizadas como otimistas e positivas. A maioria está satisfeita com as atividades agrícolas e com o meio rural, acredita na melhoria da agricultura em relação à época quando os seus pais eram agricultores e não deseja migrar para a cidade ou outro lugar no campo e valorizam a tranquilidade no espaço rural do assentamento MAISA.

\section{REFERÊNCIAS}

AMARAL FILHO, J.; Globalização, transformações estruturais, desenvolvimento local e regional, um olhar sobre o Nordeste Brasileiro. In: AMARAL FILHO, J.; CARRILLO, J. (org.). Trajetórias de Desenvolvimento Local e Regional: Uma Comparação entre a Região Nordeste do Brasil e a Baixa Califórnia (México). Rio de Janeiro: Papers, 2011. p. 35-65.

BAIARDI, A. Gênese e evolução da agricultura familiar: desafios na realidade brasileira e as particularidades do Semiárido. Revista Econômica do Nordeste, Fortaleza, v. 45, suplemento especial, p. 143-156, out./dez., 2014.

BCB - BANCO CENTRAL DO BRASIL. Manual de Crédito Rural. Brasília: BCB, 2014. Disponível em: <http://www3.bcb.gov.br/mcr/>. Acesso em: 16 set. 2014.

BUAINAIN, A. M. et al. Sete teses sobre o mundo rural brasileiro. Revista de política agrícola, Brasília, n. 2, p. 105-121, 2013. Disponível em: 〈http://goo.gl/yot2vn>.

CECAV/RN - Centro Nacional de Pesquisas e Conservação de Cavernas do Rio Grande do Norte. Proposta de criação de unidade de conservação federal Parque Nacional da Furna Feia. 2011.

DELGADO, N. G. Agronegócio e agricultura familiar no Brasil: desafios para a transformação democrática do meio rural. Revista Novos Cadernos NAEA, Belém, v. 15, p. 85-129, 2012.

GALVANESE, C.; FAVARETO, A. Dilemas do planejamento regional e as Instituições do Desenvolvimento sustentável. Revista Brasileira de Ciências Sociais, São Paulo, v. 29, n. 84, p. 73-84, fev. 2014.

GAZOLLA, M.; SCHNEIDER, S. (Orgs). Cadeias curtas e redes agroalimentares alternativos: negócios e mercados da agricultura familiar. - Porto alegre: UFRGS, 2017.

GONÇALVES NETO, W. Estado e Agricultura no Brasil: política agrícola e modernização econômica brasileira 1960-1980, São Paulo: Editora Hucitec, 1997.

GRAZIANO DA SILVA, José. A nova dinâmica da agricultura brasileira. Campinas: UNICAMP/IE, 1996.

HAYAMI, Y.; RUTTAN, V. W. Agricultural Development: an international perspective. Baltimore and London, 1985. 
HELFAND, S.; PEREIRA, V. Determinantes da pobreza rural e implicações para as políticas públicas no Brasil. In: BUAINAIN, A. M. et al. A nova cara da pobreza rural: desafios para as políticas públicas. Série Desenvolvimento Rural Sustentável, v. 16, Brasília: IICA, 2012. p. 121-159.

HIRSCHMAN, A. Estratégia do Desenvolvimento Econômico. Rio de Janeiro: Fundo de Cultura, 1961.

KAGEYAMA, A. Desenvolvimento rural: conceito e medida. Cadernos de Ciência \& Tecnologia, Brasília, v. 21, n. 3, p. 379-408, set./dez. 2004.

KEYNES, John Maynard. A teoria geral do emprego, do juro e da moeda. São Paulo: Atlas, 1982.

MALUF, R. S; REIS, M.C. Segurança alimentar e nutricional na perspectiva sistêmica. In: ROCHA, C; BURLANDY, L.; MAGALHÃES, R. Segurança alimentar e nutricional: perspectivas, aprendizados e desafios para as políticas públicas. Rio de Janeiro: Fiocruz, p.43-67, 2013.

MARSDEN, T. The condition of rural sustainability. The Netherlands, Van Gorcun, 2003.

MARQUES, F. C.; CONTERATO, M.A.; SCHNEIDER, S. (Orgs). Construção de mercados e agricultura familiar: desafios para o desenvolvimento rural, Porto alegre: UFRGS, 2016.

MARTINS, G. A.; THEÓPHILO, C. R. Metodologia da investigação cientifica para Ciências Sociais aplicadas. 2. Ed. São Paulo: Atlas, 2009. 247p.

McMICHAEL, Philip. Food regimes and agrarian questions. Practical Action Publishing: Warwickshire, 2013.

MATTEI, L. O papel e a importância da agricultura familiar no desenvolvimento rural brasileiro contemporâneo. Revista Econômica do Nordeste, Fortaleza, v. 45, suplemento especial, p. 83-91, out./dez. 2014.

MYRDAL, Günnar. Teoria Econômica e Regiões Subdesenvolvidas. $3^{\text {a }}$ Edição. Rio de Janeiro: Editora Saga, 1972.

NIEDERLE, P. A.; WESZ JUNIOR, V. J. (Orgs). As novas ordens alimentares. - Porto alegre: UFRGS, 2018.

NUNES, E. M. Reestruturação agrícola, instituições e desenvolvimento rural no

Nordeste: as dinâmicas regionais e a diversificação da agricultura familiar no Pólo AssuMossoró (RN). Tese de Doutorado, Faculdade de Ciências Econômicas da UFRGS, Porto Alegre, Rio Grande do Sul. 2009. 350p.

NUNES, E. M.; SCHNEIDER, S. Economia Agrícola, Instituições e Desenvolvimento Rural: uma análise comparativa da diversificação econômica do Pólo Assu/Mossoró (RN). Revista Econômica do Nordeste, Fortaleza, v. 43, p. 561-584, jul.-set. 2012.

NUNES, E. M.; SCHNEIDER, S. Reestruturação Agrícola, Instituições e Desenvolvimento Rural no Nordeste: a diversificação da agricultura familiar do Pólo Açu-Mossoró (RN).

Revista Econômica do Nordeste, Fortaleza, v. 44, p. 601-626, 2013. 
NUNES, E. M.; SILVA, V. M.; SA, V. C. Assistência Técnica e Extensão Rural (ATER): formação e conhecimentos para a agricultura familiar do Rio Grande do Norte. REDES (Santa Cruz do Sul. ONLINE), v. 25, p. 458-482, 2020.

OLIVEIRA, A. R. O associativismo na Região do Pontal do Paranapanema-SP: Limites e possibilidades para o desenvolvimento rural. Tese de Doutorado, Faculdade de Ciências e Tecnologia da UNESP, Presidente Prudente, São Paulo. 2010. 209p.

PAIVA, Rui Miller. Modernização e dualismo tecnológico na agricultura. Pesquisa e Planejamento, v.1, no $2,1971$.

PERROUX, F. A economia do século XX. Lisboa: Livraria Morais, 1967

PLOEG, J. D. van der; MARSDEN, T. (Eds.) Unfolding webs: the dynamics of regional rural development. Assen: Van Gorgum, 2008.

PLOEG, J. D. van der. The new pensantries: rural development in times of globalization. Second edition, London: Earthscan; Sterling VA, 2018.

SÁ, J. N. A estrada que percorri. Natal: J. N. de Sá, 2003. 282 p.

SEN, A. K. Desenvolvimento como Liberdade. São Paulo: Companhia das Letras, 2000.

SCHNEIDER, S. A pluriatividade na agricultura familiar. Porto Alegre: Editora UFRGS, 2003. 254p.

SCHNEIDER, S. Reflexões sobre diversidade e diversificação: agricultura, formas familiares e desenvolvimento rural. Revista Ruris, Campinas/SP, v. 4, n.1, mar. 2010a.

SCHNEIDER, S. Situando o desenvolvimento rural no Brasil: o contexto e as questões em debate. Revista de Economia Politica, São Paulo, v. 30, n. 3 (119), p. 511-531, jul./set. $2010 b$.

SCHUH, G.E. A modernização da agricultura brasileira; uma interpretação. ln:

CONTADOR, R.C., ed. Tecnologia e desenvolvimento agrícola. Rio de Janeiro, IPEA/INPES, 1975. p.7-45.

SILVA, C. R. F. E.; SILVA, M. R. F.; NUNES, E. M. A operacionalização do Programa de Aquisição de Alimentos (PAA), na modalidade Compra com Doação Simultânea (CDS) no território Açu-Mossoró (RN). Revista EXTENDERE, v. 5, p. 148-165, 2017.

SOUZA, N. J de. Desenvolvimento Econômico. $5^{\text {a }}$ ed. - rev. - São Paulo: Atlas, 2005. 